\title{
A Relationship between Road Conditions, Physical and Psychophysical Experience among Occupational Drivers
}

\author{
Seri.Rahayu. $\mathrm{K}^{1, \mathrm{a}}$ and Fatihah Ros Ahmad ${ }^{1, \mathrm{~b}}$ \\ ${ }^{1}$ Faculty of Manufacturing Engineering, \\ Universiti Teknikal Malaysia Melaka, Durian Tunggal, 76100 Melaka, Malaysia \\ Phone: +606-3316447, Fax: +606-3316411, \\ aseri@utem.edu.my , ${ }^{\mathrm{b}}$ intan_fatin89@yahoo.com
}

Keywords: Sitting posture, comfort, fatigue and musculoskeletal pain.

\begin{abstract}
Nowadays, back pain has contributed huge percentage to Malaysian drivers during driving. Bad or awkward sitting posture may cause fatigue and musculoskeletal pain to the driver due to long distance driving or maintained for a long time. Therefore, it is essential to do the survey on the impact of these elements for the driver based on our Malaysian road conditions. The objective of this paper is to investigate the relationship between different physical categories (age, height, weight and gender) and psychophysical experience on focusing with the degree of comfort ability drivers on Malaysian road condition. The survey should be conducted in random by taking sample from difference categories of drivers in order to get fair result. The experiment has been conducted to define the effect factors of level comfort during thirty minutes driving on the actual road. The result show, aging is one of the factors have significantly higher absolute discomfort for drivers aging from 43 to 53-54 years old with driving in the descending road. In the other hand it is shows that the discomfort ability of drivers can be influences by the driving experience, weight, height and gender of the drivers. Thus, it can be conclude, Malaysian drivers mostly feel discomfort when driving at the descending road and winding road compare to two others road.
\end{abstract}

\section{Introduction}

Many previous researches are interested on musculoskeletal disorder injuries especially among drivers and more on the experimental in the lab only. Musculoskeletal pain may affect bones, muscle or ligament of body by two ways either acute or chronic. Several studies show, the large percentage of all occupational injuries occurring in the upper extremities. The examples of the injuries can occur with prolonged sitting are low back pain [1] and neck pain [2]. Even though professional drivers, they are also expose to musculoskeletal pain and injuries in many ways and means. Some other studies found that falling asleep at the wheel is one of the leading causes of fatal accidents and injuries [3]. Posture is ones of the factors to determine amount of fatigue experience by the performance or drivers. [4] and [5]. The force given by body has been claims can directly relate to fatigue [6]. Therefore, fatigue can be measure by calculated the twitch force (movement force). This statement has been admitted by previous studies by state that force can be related with muscle fatigue. However, the types of grip when held an object also plays an important role to accelerate the muscle fatigue [7] and [8]. Thus, it is means the force applied at the steering wheel also can measure the level fatigue.

Others studies also have related others factors with fatigue experience by drivers such as types of road [9], driving experience [10] and age of the drivers [11]. The types of road or the environment of road can plays an important role to reduce the drivers' fatigue [9] and [11]. The road with rough surface will expose the drivers to vibration which is one of the biomechanical factors as travelling increase. Along with the injury, vibration can make drivers feel discomfort and fatigue [12]. For addition, fatigue may increase at the complex road with high load traffic compare to monotonous road low load road environments [13]. Beside types of road, the professional drivers who usually have high driving experiences mostly can gain extensive experience in a relatively short period of 
time compared to nonprofessional driver [10]. However, each country will present different features and habit when driving. Thus, this study is focus on Malaysia drivers' group. The survey will be conducted to know the behaviour and driving experience of Malaysia drivers.

\section{Method}

There are two method has been conducted in this study which are survey method and experimental method.

For this particular survey, samples are pick-up within a group of Malaysian taxi driver. These group is selected because it is easier to communicate and very responsive. Sixty of them are chosen by random between ages 20 to 65 years old presented by all races. Five categories of physical information are identified in the questionnaire as the basic information of the driver (participant). The categories chosen are driving experience, aging, weight, height and gender.

For the experimental method, nine respondents were taken between ages 20 to 29 years old. The whole body vibration is place on the driver seat while respondents are driving in village road with thirty minute. After finish the experiment, the respondents should fill up the questionnaire base on their driving experience. The result from the vibration equipment and survey on level of comfort will be used to identify the discomfort experience on the body part of the respondent. There are fourteen part of upper body are included in the survey which are Rt SCM, Lt SCM, [14] Rt ANT deltoid, Lt ANT deltoid, Rt biceps br, Lt biceps br, Rt abduct pol, Lt abduct pol, Lt cervical ps, Rt cervical ps, Lt upper trap, Rt upper trap, Lt lumbar es and Rt lumbar es.

\section{Experimental procedures}

The short briefing is given to all participants on order to make them clear the survey objective and an important of honestly answer the questionnaire. The questionnaires have separated by two section; physical information of the participant and their physical experience during driving. No time limits are given and participants are ensuring on identification privacy.

Eighty types of questionnaires are identified by the participant on the physical information including driving experience, comfort ability during driving on Malaysian road and discomfort experience due to long driving. The questionnaires on the road are divided into four difference situation/condition which is ascending, descending, straight and winding. In order to make easier for participant to answer, likert scale is applied for all questionnaires. "The likert scale was used in this study due to the fact that the likert scale can collect and analyse a large quantity of data with less time and effort [15].

\section{Results and Discussion}

The statistical analysis result from the questionnaire data gives information on comfort ability show in Figure 1. From the histogram result, the comfort ability answers by participants compares to physical information and figure 2 shows in vice visa. 


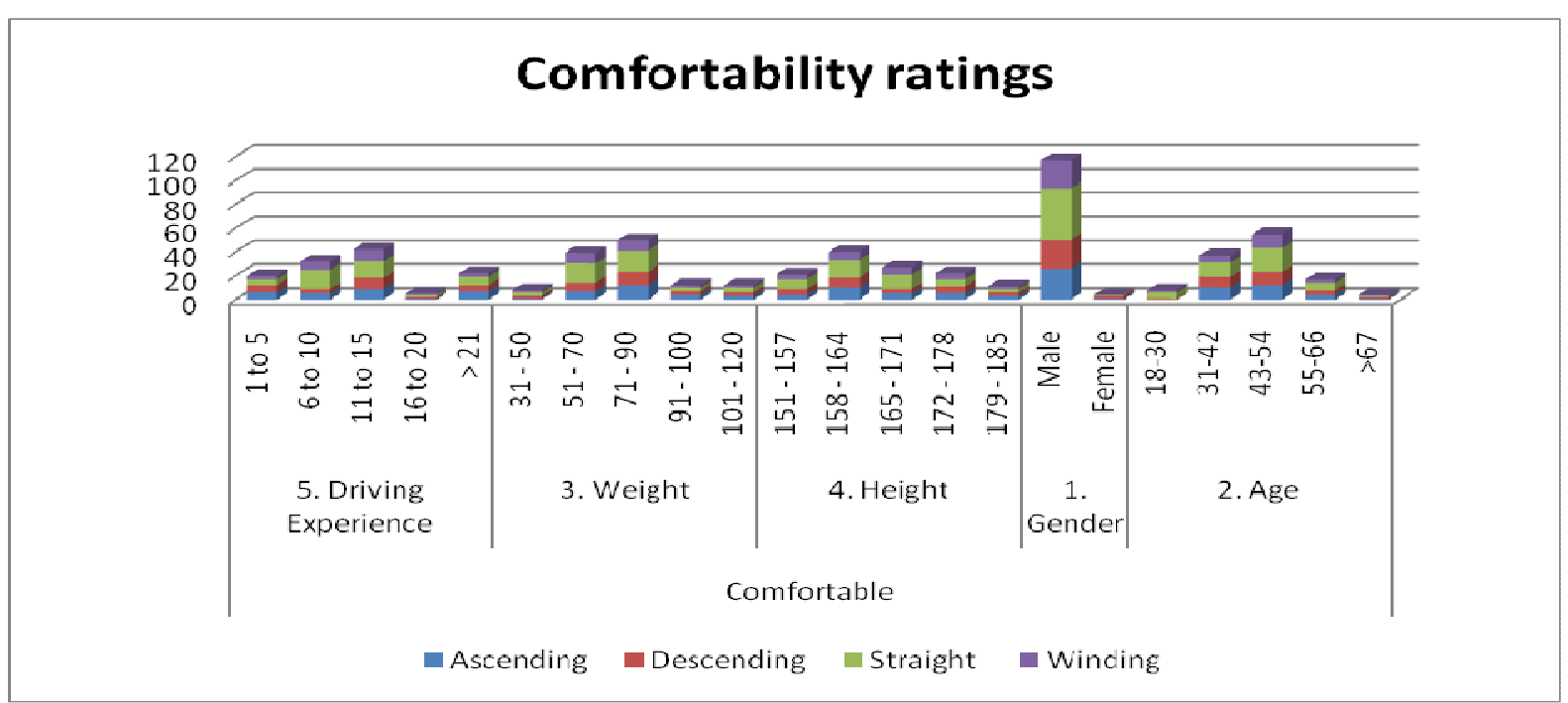

Fig. 1: Histogram of comfortability of drivers against difference road conditions

Figure 1 shows the comfort ability for male drivers with aging range 43 to 54 and have driving experience between 11 to 15 years. Their weight is between 71 and $90 \mathrm{~kg}$ with height of 158 to 164 $\mathrm{cm}$. The result for the long driving shows, most of the participants are more comfortable while driving on the straight road compare to others roads.

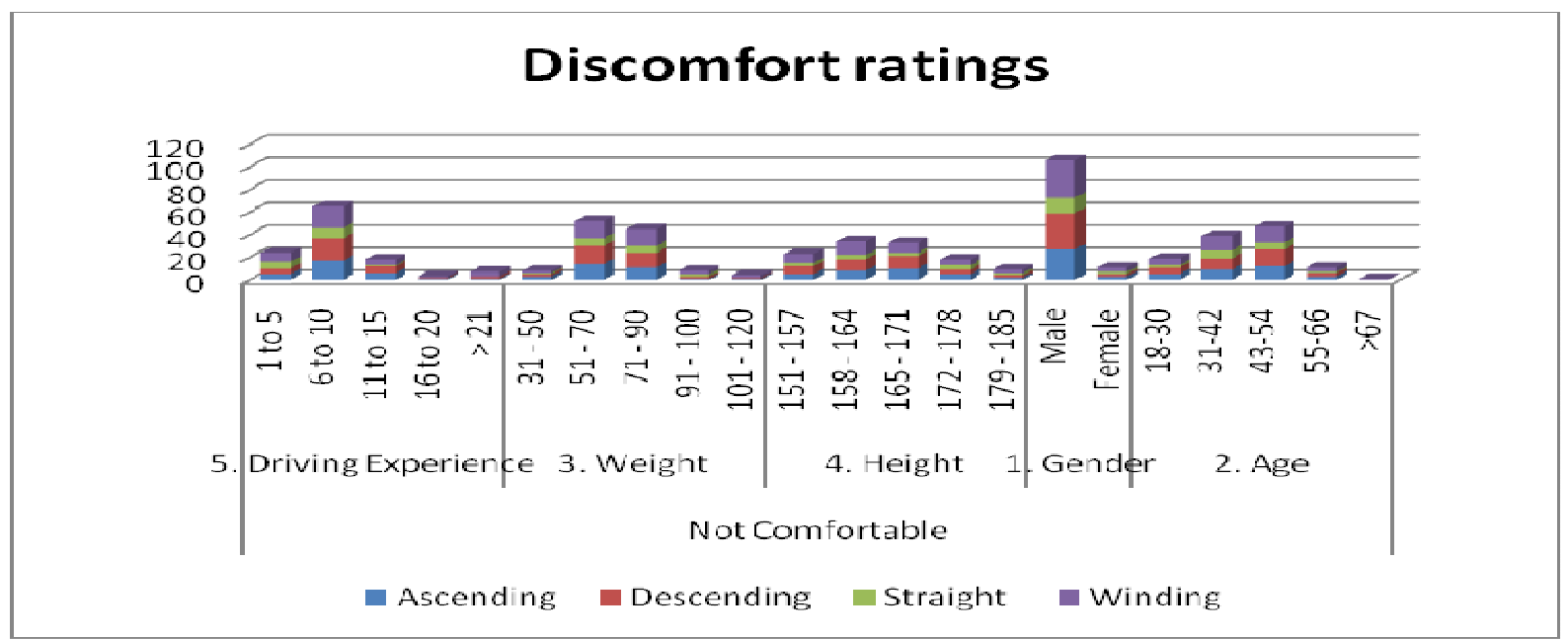

Fig. 2: Histogram of discomfort of drivers while driving in difference road conditions.

The result form the histogram show the factor that give an effect for discomfort feeling while driving can be categories into 4; gender, age, driving experience, weight and height. The result from the genders shows the discomfort ability male drivers between ages 43 to 54 while driving in descending road. However, some of the participants which have driving experiences between 6 to 10 years have a similar feeling discomfort on the descending road. It is different from the weight and height, the drivers with has weight between $51 \mathrm{~kg}$ and $70 \mathrm{~kg}$ and height between $158 \mathrm{~cm}$ to $164 \mathrm{~cm}$ has noted discomfort feeling while driving on the winding road.

In order to determine whether personal information had any influence to the comfort ability of Malaysian driver, 2 type hypotheses had been created for 4 categories of personal information. After that, the $\mathrm{p}$ value will be calculated by using Minitab Software, as tools to check the hypothesis. List of hypothesis are as follows:-

$\mathrm{H}_{0}$ a: Driving experiences can influence discomfort of drivers while driving.

$\mathrm{H}_{1}$ a: Driving experiences cannot influence discomfort of drivers while driving.

$\mathrm{H}_{0}$ b: Age of drivers can influence discomfort of drivers while driving.

$\mathrm{H}_{1} \mathrm{~b}$ : Age of drivers cannot influence the discomfort of drivers while driving. 
$\mathrm{H}_{0} \mathrm{c}$ : Weight of drivers can influence the discomfort of drivers while driving.

$\mathrm{H}_{1} \mathrm{c}$ : Weight of drivers cannot influence the discomfort of drivers while driving.

$\mathrm{H}_{0} \mathrm{~d}$ : Height of drivers can influence the discomfort of drivers while driving.

$\mathrm{H}_{1} \mathrm{~d}$ : Height of drivers cannot influence the discomfort of drivers while driving.

Table 1: F-values and P-values

\begin{tabular}{|c|l|c|c|}
\hline Bil & \multicolumn{1}{|c|}{ Source } & F values & P values \\
\hline 1 & Driving Experiences & 33.04 & 0.000 \\
\hline & Types of road & 3.73 & 0.042 \\
\hline 2 & Age of drivers & 35.38 & 0.000 \\
\hline & Types of road & 5.28 & 0.015 \\
\hline 3 & Weight & 32.68 & 0.000 \\
\hline & Types of Road & 4.22 & 0.030 \\
\hline 4 & Height & 5.43 & 0.011 \\
\hline & Types of Road & 6.42 & 0.013 \\
\hline
\end{tabular}

The statistic analysis result shows the $\mathrm{p}$ values of 0.05 is the turning point either to accept or reject the hypothesis. When the calculations done by referring the table 1 the $\mathrm{p}$ value for hypothesis $\mathrm{H}_{\mathrm{oa}}$ is 0.04 are below turning point, therefore the hypothesis is accepted. So do for hypothesis $\mathrm{H}_{\mathrm{ob}}$, $\mathrm{H}_{\mathrm{oc}}$ and $\mathrm{H}_{\mathrm{od}}$ with the $\mathrm{p}$ value is $0.015,0.03$ and 0.013 respectively. Then, by all the $\mathrm{p}$ value below par, all selective personal information such as driving experiences, age, weight and height of the drivers can influence the discomfort ability of the drivers while driving all type of road condition.

The physical information as presented by chosen the elements had influence the comfort abilities of the driver while driving. As such, it is possible that the same happen to other physical element such as type of chairs, the fabric used, and driving space and cars accessories. It also had role to ensure comfort abilities of the drivers. Therefore, is needed to improving the designed and feature in order to meet the driver comfort ability during driving. As driving comfort ability is closely related to road accidents, and then the survey is become essential.

Figure 3 shows the relationships of physical drivers, level of comfort and vibration during thirty minutes of driving on the actual road. One of the responder (Hazwan) shows the high level of comfort ability and received high vibration. Meanwhile other one responder (Iqbal) shows the low level of comfort ability and received low vibration compared to other respondent.

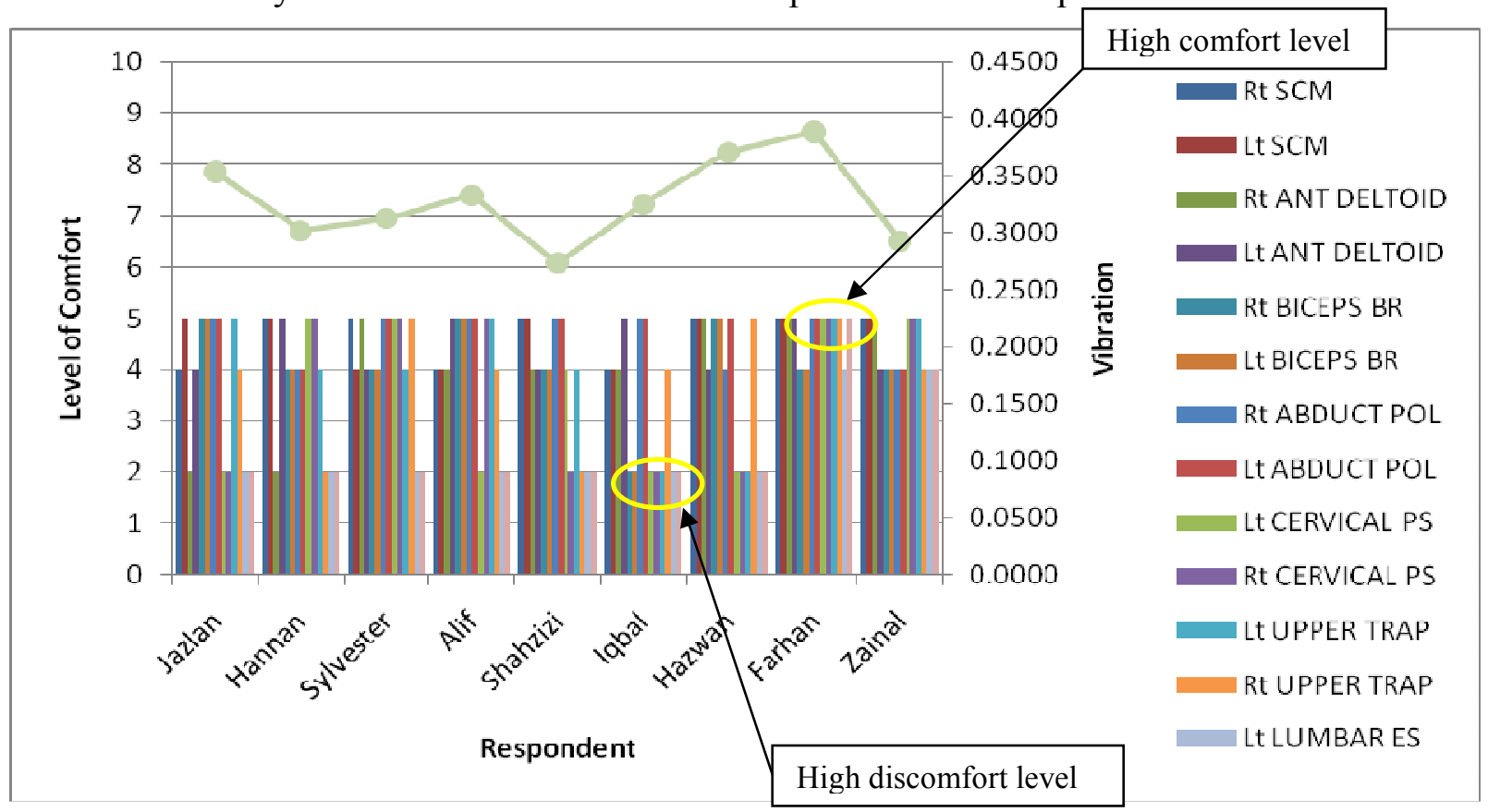

Fig. 3: Relationship between level of comfort, respondents and vibration during thirty minutes of driving. 
Interestingly, from the pilot study reveals a relationship between heights of respondent with the level of comfort during thirty minutes of driving. This result can be seen by comparing the graft in figure 3 and 4. By highlighted the result from Hazwan and Iqbal, it is shows that the vibration cannot give an affect of the comfort ability for the drivers. Meanwhile the factor of height shows vice versa.

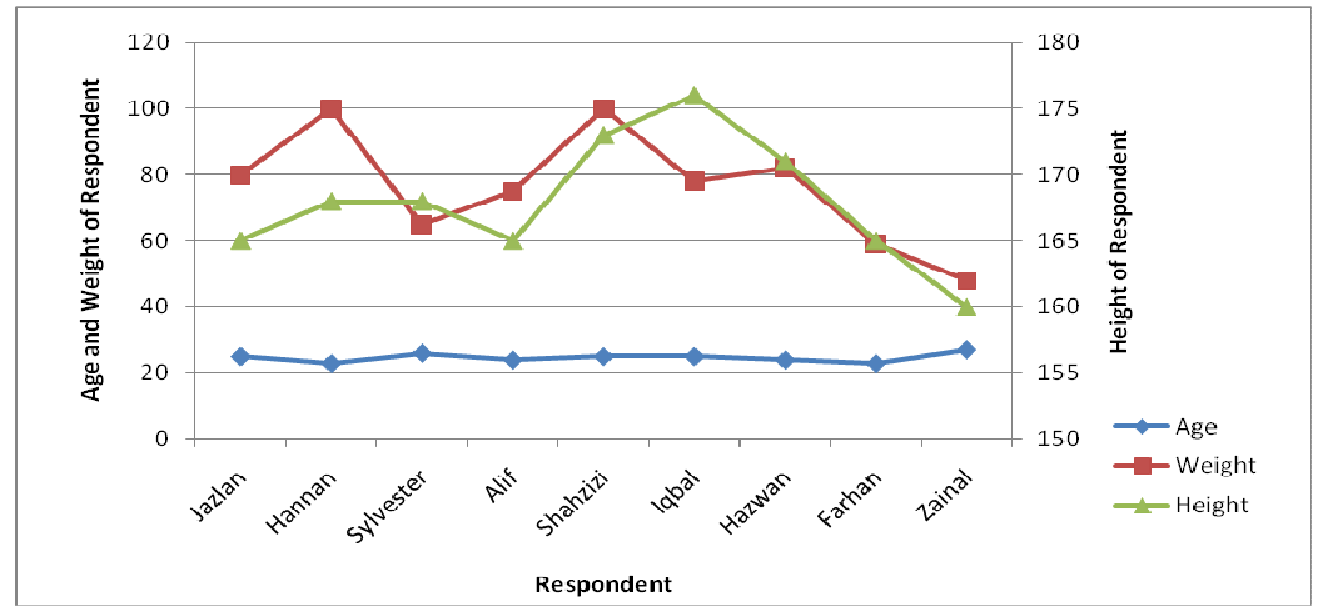

Fig. 4: Relationship between age and weight of respondent with height of respondent.

From the actual experiment, the vibration will not show an effect on the level of comfortable. However, the driver's height shows an effect on the level of comfort. This may due to the facts that, height of respondent can give awkward posture to the drivers while driving. The drivers might have to bend their body to avoid their head touch the roof of car. It is similar with the result from survey which the tall drivers noted discomfort feeling while driving on the winding road. So that, it can confirm that the drivers height is one of the important factor for the discomfort experience while driving car.

\section{Conclusion and Future Work}

The study conclude that, the four categories are important to investigate the drivers discomfort ability, which are driving experiences, aging, weight and height while driving in the different kind of road. The most discomfort ratings in driving experiences, aging and weight categories claims, they felt most discomfort while driving in the descending road. Nevertheless, the high discomfort ratings in the height categories state that, they felt most discomfort while driving in the winding road. The tall drivers with height at least $158 \mathrm{~cm}$ are felt discomfort due to their unstable posture while driving in the winding road. Hence for future work, the research will be continue with related the awkward posture of the drivers while driving in the descending road and winding road by taking their muscle activity rate to detect the comfort ability and driving fatigue.

\section{Acknowledgements}

This study was funded by My Brain UteM, S01057 and Center for Research and Innovation Management (CRIM). We thank the representatives of all cab drivers at Melaka Central for valuable support during the survey session. 


\section{References}

[1] J.M.Porter and D.E.Gyi, The prevalence of musculoskeletal troubles among car drivers, Occupational Medicine (Lond). 52(2002) $4-12$.

[2] M.Massaccesi, A.Pagnotta, A.Soccetti, M.Masali, C.Masiero, F.Greco, Investigation of work related disorders in truck drivers using RULA method, Applied Ergonomics. 34 (2003) 303-307

[3] K.Karrer, M.Roetting, Effects of Driver Fatigue Monitoring: An Expert Survey, Springer, Berlin/Heidelberg. (2007) 324-330.

[4] S.A.R.AL-Dubai, A.M.Qureshi, N.H.Ismail and K.G.Rampal, Prevalence and determinants of low back pain among taxi drivers in Malaysia: A cross sectional study, Design for Scientific Renaissance. 2(4) (2012) 129-143

[5] A.Finneran and L.O'Sullivan, Effects of grip type and wrist posture on forearm EMG activity, endurance time and movement accuracy, International Journal of Industrial Ergonomics. 43(1) (2013) 91-99

[6] D.Barry, T.Hill and D.Im, Muscle fatigue measured with evoked muscle vibrations, Muscle nerve. 15(3) (1992) 303-309.

[7] A.Augurelle, A.M.Smith, T.Lejeune, J.Thonnard, Importance of continuous feedback in maintaining a secure grip during manipulation of hand-held objects, J. Neurophysiol. 89 (2) (2003) 665-671.

[8] M.Hagberg, B.Silverstein, R.Wells, M.J.Smith, H.W. Hendrick, P.Carayon, M.Perusse, Work Related Musculoskeletal Disorders (WMSDs): a Reference Book for Prevention, Bristol Taylor and Francis. (1995)

[9] M.Eksioglu and K.Kizilaslan, Steering Wheel grip force characteristics of drivers as a function of gender, speed, and road condition, International Journal of Industrial Ergonomics. 38(3-4) (2008) 354-361

[10] P.Gershon, D.Shinar, T.Oron-Gilad, Y.Parmet and A.Ronen, Usage and perceived effectiveness of fatigue countermeasures for professional and nonprofessional drivers, Accident, analysis and prevention. 43(3) (2011) 797-803

[11] D.Clarke, P.Ward and J.Jones, Overtaking road accidents: differences in manoeuvre as a function of driver age, Accident, analysis and prevention. 30(4) (1998) 455-467

[12] Y.Cho and Y.S.Yoon, Biomechanical model of human on seat with backrest for evaluating ride quality, International Journal of Industrial Ergonomics. (2001) 331-345

[13] Y.Liu, and T.Wu, Fatigued driver's driving behaviour and cognitive task performance: Effect of road environments and road environment changes, Safety Science. 47(8) (2009) 1083-1089

[14] S.H.Min, S-H.Chang, S.K.Jeon, S.Z.Yoon, J.Y.Park and H.W.Shin, Posterior auricular pain caused by the trigger points in the sternocleidomastoid muscle aggravated by psychological factors, Korean J Anesthesiol. 59 (2010)

[15] Q.Li, A novel Likert scale based on fuzzy sets theory. Expert System Application, an International Journal.40 (5) (2013) 1609-1618

[16] S.B.M. Tamrin, K. Yokoyama, J. Jalaludin, N.A. Aziz, N. Jemoin, R. Nordin, A. Li Naing, Y. Abdullah and M. Abdullah, The association between Risk Factors and Low Back Pain among Commercial Vehicle Drivers in Peninsular Malaysia: A Preliminary Result, Industrial Health. (2007) 268-278.

[17] V.Kaushik and N.Charpe, Effect of body posture on stress experienced by worker, Stud Home Comm Sci., 2(1) (2008) 1-5 